\title{
自己中心的視点からの把持行為の観察による 視覚注意の調整効果
}

\section{望月 正哉 玉木 賢太郎 内藤 佳津雄 日本大学}

\section{Observing grasping action from egocentric perspective modulates observer's visual attention}

\author{
Masaya Mochizuki, Kentaro Tamaki, and Katsuo Naito (Nihon University)
}

\begin{abstract}
Previous studies demonstrated that observing another person's grasp action modulated the observer's attention to the object in a manner congruent with another person's action goal. These studies suggest that this grasp-cueing effect results from representation of the observer's understanding of action intention in the mirror neuron system. This system serves as the neural mechanism underlying action-oriented goals, regardless of whether they are those of the observer or others. The present study examined whether the grasp-cueing effect emerged even when a grasp action was observed from an egocentric (observer's own) perspective. Reaction times were faster when the target was presented over the object that was congruent with the action goal implied by the size of the hand aperture. This indicated that the grasp-cueing effect occurred when the stimulus was observed from an egocentric perspective, consistent with the view that this effect resulted from the observer's understanding of action intention as represented in the mirror neuron system.
\end{abstract}

Key words: action observation, mirror neuron system, egocentric perspective.

The Japanese Journal of Psychology

2014, Vol. 85, No. 4, pp. 398-403

J-STAGE Advanced published date: August 1, 2014, doi.org/10.4992/jjpsy.85.13320

社会的相互作用の場面では，情報伝達に言語的情報 だけでなく，身体的な動作も用いられる。そのような 場面での行為の観察は, 観察者に行為者の注意の方向 や意図を推測させる (Frischen, Bayliss, \& Tipper, 2007）。例えば，他者の視線の向きによって，その方 向への注意が促進されることが示されている（Nuku \& Bekkering, 2008; Ristic, Friesen, \& Kingstone, 2002)。 このような促進的効果は共同注意 (joint attention) に よって起こるものであるとされ，視線を行動の手がか りとして, 観察者が意図を共有しょうとする特性が反 映されているものと考えられる。

このような他者の行為の観察による視覚処理の調整 効果は, 視線だけでなく, 他者が見せている舌の向き (Downing, Dodds, \& Bray, 2004）や他者の指差し方向 （Fischer \& Szymkowiak, 2004）を手がかりとした場合

Correspondence concerning this article should be sent to: Masaya Mochizuki, College of Humanities and Sciences, Nihon University, Sakurajosui, Setagaya-ku, Tokyo 156-8550, Japan (e-mail: mochi-ma@ chs.nihon-u.ac.jp)
にも起こることが報告されている。Fischer \& Szymkowiak（2004）は, 画面上に提示される三つの 対象物のうち, 一つの対象物の色が変化した際に参加 者にボタンを押させる課題において, 対象物とともに 指差し行為をする手を提示することにより，その指差 し方向に一致した対象物の色変化を速く検出できるこ とを示した。

これらの研究で手がかりとして提示される行為は, 知覚対象へ視覚注意を促すために直接的な方向指示性 をもつものであるが, 近年の研究では, 直接的な方向 指示性をもたない（推測的な）行為でも視覚注意の調 整が起こることが示されている。Fischerら（Fischer, Prinz, \& Lotz, 2008; Tschentscher \& Fischer, 2008）は, 把 持行為をする手を見たときに，その手の開く大きさに 一致する大きさの対象物に対して視覚的な注意が向け られることを示した。例えば, Fischer et al. (2008) で は，参加者は画面上から画面中央に伸びる，ものを摘 む手（precision grip）やものを掴む手（power grip）を 観察したあとに，その手の近くにある大きさの異なる 二つの対象物のいずれかの上に提示されるターゲット 
刺激を検出した際にスペースバーを押す単純反応課題 を行った。その結果, 遅延時間 $200-300 \mathrm{~ms}$ で, 手 のかたちに一致する大きさの対象物上に提示された ターゲット刺激への反応時間が, 一致しない大きさの 対象物上に提示されるターゲット刺激への反応時間よ りも短かった。これを Fischerらは把持手がかり効果 (grasp-cueing effect) と呼んだ。さらに, ターゲット 刺激が手のかたちに一致する大きさの対象物上に出る 確率を下げた場合 $(20 \%)$ でも同様の効果がみられる ことを示し，注意の調整が自動的であることを示唆し た。

Fischer et al.（2008）は，これらの結果がミラーニュー ロンシステム (mirror neuron system: Rizzolatti \& Craighero, 2004）に基づく行為シミュレーションによって起こる ものであると主張している。ミラーニューロンシステ ムはマカクザルの F5 領域でみられたミラーニューロン (Gallese, Fadiga, Fogassi, \& Rizzolatti, 1996) と同様の機構 をもつヒトの神経回路で, 特定の行為を自身が遂行す る際にも，他者が遂行する行為を観察する際にも活動 を示すとされるものである。Fischer et al. (2008) は, ヒトが特定の手のかたちを観察することで, ミラー ニューロンシステムで行為のシミュレーションが行わ れ，手のかたちに一致する対象物を取ろうとしている という意図を理解し, その対象物へ注意が向けられる と説明している。

行為のシミュレーションにより注意が調整されると いう考えに一致する結果として, Lindemann, Nuku, Rueschemeyer, \& Bekkering（2011）は把持手がかり効 果に手の行為を観察することが重要であることを指摘 している。Lindemann らは単純反応課題に扔ける手が かりとして把持行為の写真に加え, 開きの大きさは手 の刺激と同様だが抽象的な U 字型を用いた。実験の 結果, 把持行為の写真では把持手がかり効果がみられ たが，U 字型の刺激ではそのような効果はみられな かった。この結果から彼らは, 把持手がかり効果が, 手や U 字型の開きの大きさと対象物の大きさの知覚 的な一致性に基づいて起こるのではなく, 行為の観察 を通じて行為の意図を理解しようとすることで起こる 可能性を示唆している。

Fischer et al. (2008) と Lindemann et al. (2011) の 研究は, 実験刺激に視線や指差し行為などの方向性が 明示的な手がかり刺激ではなく，より推測的であると いえる把持行為を刺激に用いている点が重要である。 Jansson, Wilson, Williams, \& Mon-Williams（2007）は, 他者の行為観察によって行為の模倣が促進される現象 について検討した研究で，その効果が，(刺激の）方 向性, 視覚的明示性, 刺激反応適合性など様々な要因 が混交しているものであることを指摘している。指差 し行為は, その行為の意図（特定の対象物について何 らかの関わりをもとうとしていること）を示すことで
処理を促進させると考えられる一方で, 低次の知覚的 な明示性（例えば, 指の形が矢印の役割を果たしたり, 対象物と手との物理距離が近くなったりすること）に よっても处理が促進されている可能性も考えられる。 しかし, Fischer et al. (2008) と Lindemann et al. (2011) は直接的には方向性を明示しない把持行為を用いるこ とで, 行為の観察による視覚注意の調整にミラー ニューロンシステムが関与していることを示唆してい る。

これらの研究は, 他者の行為を向かい側から観察す るような場面（他者中心的視点）を刺激に用いている。 しかし, Fischer et al.（2008）が主張するように, 把 持行為の観察による視覚注意の調整効果がミラー ニューロンシステムに基づく行為の意図の理解による ものであるのならば，自己の行為を観察するような場 面 (自己中心的視点) の刺激でも同様の効果が起こる ものとも考えられる。

実際, Belopolsky, Olivers, \& Theeuwes（2008）の研 究はこの考えと一致している。この研究では, 単純反 応課題を用い, 他者中心的視点の指差し行為の刺激と ともに, 自己中心的視点の指差し行為の刺激でも, 視 覚注意の調整が起こるかどうかを検討した。ここでは, 他者中心的視点の刺激として，机の反対側から他者が 指差し行為をする姿を見るような写真と，自己中心的 視点の刺激として, 机の手前側から人物が指差し行為 をする（自己が指差し行為を遂行しているように見え る）写真が用いられた。実験の結果，他者中心的視点 の刺激に加え, 自己中心的視点の刺激でも行為と一致 する方向の対象物の変化への反応時間のほうが短くな ることを示した。このことから，行為の観察は他者が 遂行しているものの場合も, 自己が遂行している(よ うに見える）ものの場合でも，同様の調整効果をもた らすと考えられる。

しかし, 自己中心的視点からの把持行為の観察が視 覚注意に与える影響について検討した研究はみられな い。そこで本研究では把持行為の観察による視覚注意 の調整が, 自己中心的視点からの手の観察でも起こる のかどうかを検討した。具体的には，自己中心的視点 で把持行為をする写真をターゲット刺激提示の合図と して提示して，対象物上に提示されるターゲット刺激 へのボタン押しを求める単純反応課題を実施した。 Fischer et al. (2008) や Lindemann et al. (2011) に基 づくと, 把持行為を観察することで, その行為の意図 と一致する対象物へ注意が向き，把持の大きさに一致 する大きさの対象物上に提示されるターゲット刺激へ の反応時間が，意図とは一致しない対象物（把持の大 きさに一致しない大きさの対象物）上に提示される ターゲット刺激への反応時間よりも短くなると考えら れる。 


\section{方 法}

\section{実験参加者}

18 歳から 32 歳の 33 名が実験に参加した（平均 23.7 歳, 女性 21 名, 男性 12 名)。いずれの参加者も 自己報告により矯正を含めて視力は正常であった。ま た，1名が左利きであった以外は右利きであった。こ れらの参加者には実験の開始前に書面で参加の同意を 得た。

\section{実験計画}

ターゲット刺激の一致性 (一致, 不一致) と SOA (200 $\mathrm{ms}, 300 \mathrm{~ms}, 500 \mathrm{~ms}$ ）の 2 要因実験参加者内計画であっ た。ターゲット刺激の一致性における一致条件は手の かたちから把持対象と推測される対象物上にターゲッ 卜刺激を提示する条件, 不一致条件は手のかたちから 把持対象とは推測されない対象物上にターゲット刺激 を提示する条件とした（Figure 1)。SOA については Fischer et al. (2008) と Lindemann et al.（2011）を参 考に決定した。

\section{装置}

刺激提示と反応取得は 15.4 型ディスプレイ $(1,024$ $\times 768$ pixel）をもつラップトップ PC（Lenovo T500） と内蔵キーボードを用いた。提示制御と反応記録には E-Prime ver. 2.0（Psychology Software Tools, Inc.）を用 いた。

\section{提示刺激}

実験では，大きさが異なるが片手で把持できる対象 物（大きな対象物（リンゴ）と小さな対象物（ミニト マト)）と，自己中心的視点の右手の写真を提示した。 自己中心的視点の操作として, Belopolsky et al. (2008) や，認知処理における視点の影響について検討した Bruzzo, Borghi, \& Ghirlanda（2008）を参考に，手が画 面下側から画面中央に伸びる写真を用いることとし た。対象物は，画面提示でそれぞれ大きな対象物が画 面上で $24 \mathrm{~mm}$ 四方 $(90 \times 90$ pixel $)$, 小さな対象物が $8 \mathrm{~mm}$ 四方 $(30 \times 30 \mathrm{pixel})$ に収まる大きさであった $($ 視 角でそれぞれ $2.3^{\circ}$ と $\left.0.8^{\circ}\right)$ 。手の写真は対象物の大き さに対応する把持行為をしていた。大きな把持(以下, 掴み写真とする)の指のひらき幅は画面上で $30 \mathrm{~mm}$ (視 角 $2.9^{\circ}$ ), 小さな把持 (以下, 摘み写真とする) は 10 $\mathrm{mm}$ (視角 $1^{\circ}$ ) であった。また，把持行為の写真の前 後に提示する刺激として拳を握っている状態の写真 （以下, 安静写真とする）も作成した。ターゲット刺 激は $14 \mathrm{~mm}$ 四方 $\left(52 \times 52 \mathrm{pixel}\right.$, 視角 $\left.1.3^{\circ}\right)$ に収まる 赤色の星型であった (Figure 1)。

\section{手続き}

実験は個別に行った。参加者は PC が置かれた机の 前に座り，実験参加および内容の教示を受けた。この とき, 参加者からディスプレイまでの距離は約 $60 \mathrm{~cm}$ となるように調整した。教示が終わると参加者は単純 反応課題を行った (Figure 1)。各試行では始めに 1,500 $\mathrm{ms}$ 間空白画面を提示し, 続いて二つの対象物と安静 写真を提示した。ここでの提示時間は参加者が手のか たちにより注目するよう $1,000-2,000 \mathrm{~ms}$ の間でラン ダムとした。続いて, 把持行為の写真（掴み写真ない し摘み写真）を $150 \mathrm{~ms}$ 提示した。把持行為の写真の 提示が終わると, 再び安静写真を提示した。このあと 二つの対象物上のどちらかにターゲット刺激を提示し た。ターゲット刺激提示までの時間は SOA で 200 $\mathrm{ms}, 300 \mathrm{~ms}, 500 \mathrm{~ms}$ のいずれかであった。参加者には, 手のかたちの変化がターゲット刺激提示の合図である ため注視するよう教示し, その後どちらかの対象物上 にターゲット刺激が提示されたら, 右手でスペース バーを押すように求めた。把持行為の写真の提示後は 注視位置について教示は行わなかった。参加者がス ペースバーを押す，もしくは把持行為の写真の提示終 了後 $1,500 \mathrm{~ms}$ 経過したら 1 試行が終了し, 次の試行 を開始した。

本試行では各条件を 16 試行ずつ行うとともに，課 題に集中させるために, ターゲット刺激を提示しない キャッチ試行を 8 試行実施した。キャッチ試行では ターゲット刺激が提示されないため, 参加者にはス ペースバーを押さないよう教示した。各試行はランダ ム順で実施した。本試行に先立ち，同様の手続きだが 把持行為の写真ではなく正面へ指差し行為をしている 写真を提示する練習試行を 8 回行い, 参加者はあらか じめ課題に慣れた。

\section{結果}

キャッチ試行での誤反応は全参加者で $0-3$ 試行と なり, 著しく課題に集中していない参加者はいなかっ たと判断し, 全員を分析対象とした。従属変数は, ター ゲット刺激が提示されてからスペースバーが押される までの反応時間であった。分析に際し Fischer et al. （2008）に従い， $100 \mathrm{~ms}$ 以上で各参加者の平均反応時 間から+2.5SD 以内の試行を分析対象とし，それ以外 の試行は外れ值とした。この基準に基づき, 全参加者 のターゲット刺激が提示される試行から $2.2 \%$ のデー 夕を除去した。

そのうえで実験計画に基づき，条件ごとに平均反応 時間と $95 \%$ 実験参加者内信頼区間（Loftus \& Masson, 1994）を求めたものを Figure 2 に示す。

これらの結果について 2 (一致性 : 一致, 不一致) $\times 3 （ \mathrm{SOA}$ : $200 \mathrm{~ms}, 300 \mathrm{~ms}, 500 \mathrm{~ms})$ の実験参加者 
内分散分析を実施した結果，SOA の主効果 $(F(1.75$, $\left.56.02)=21.07, M S e=350.39, p<.001, \eta_{\mathrm{p}}{ }^{2}=.40\right)$ と交 互作用 $\left(F(2,64)=4.93, M S e=115.42, p=.01, \eta_{\mathrm{p}}{ }^{2}=\right.$ .13）が有意であった。ターゲット刺激の一致性の主 効果は有意ではなかった $(F(1,32)=2.37, M S e=$ $\left.83.77, p=.13, \eta_{\mathrm{p}}{ }^{2}=.07\right)$ 。交互作用に基づき単純主効果 検定を行った結果, 一致条件と不一致条件のそれぞれ
でSOAの単純主効果が有意であった（一致条件：F $(1.57,50.39)=29.13, M S e=194.98, p<.001, \eta_{\mathrm{p}}{ }^{2}=.48 ;$ 不一致条件 : $F(2,64)=9.53, M S e=268.57, p<.001$, $\left.\eta_{\mathrm{p}}^{2}=.23\right)$ 。Shaffer 法による多重比較の結果, 一致条 件では, SOA $200 \mathrm{~ms}$ はSOA $300 \mathrm{~ms}$, SOA $500 \mathrm{~ms}$ よ り有意に反応時間が長く（それぞれ $t(32)=9.11, p$ $<.001, d=0.50, t(32)=5.21, p<.001, d=0.46)$, 不

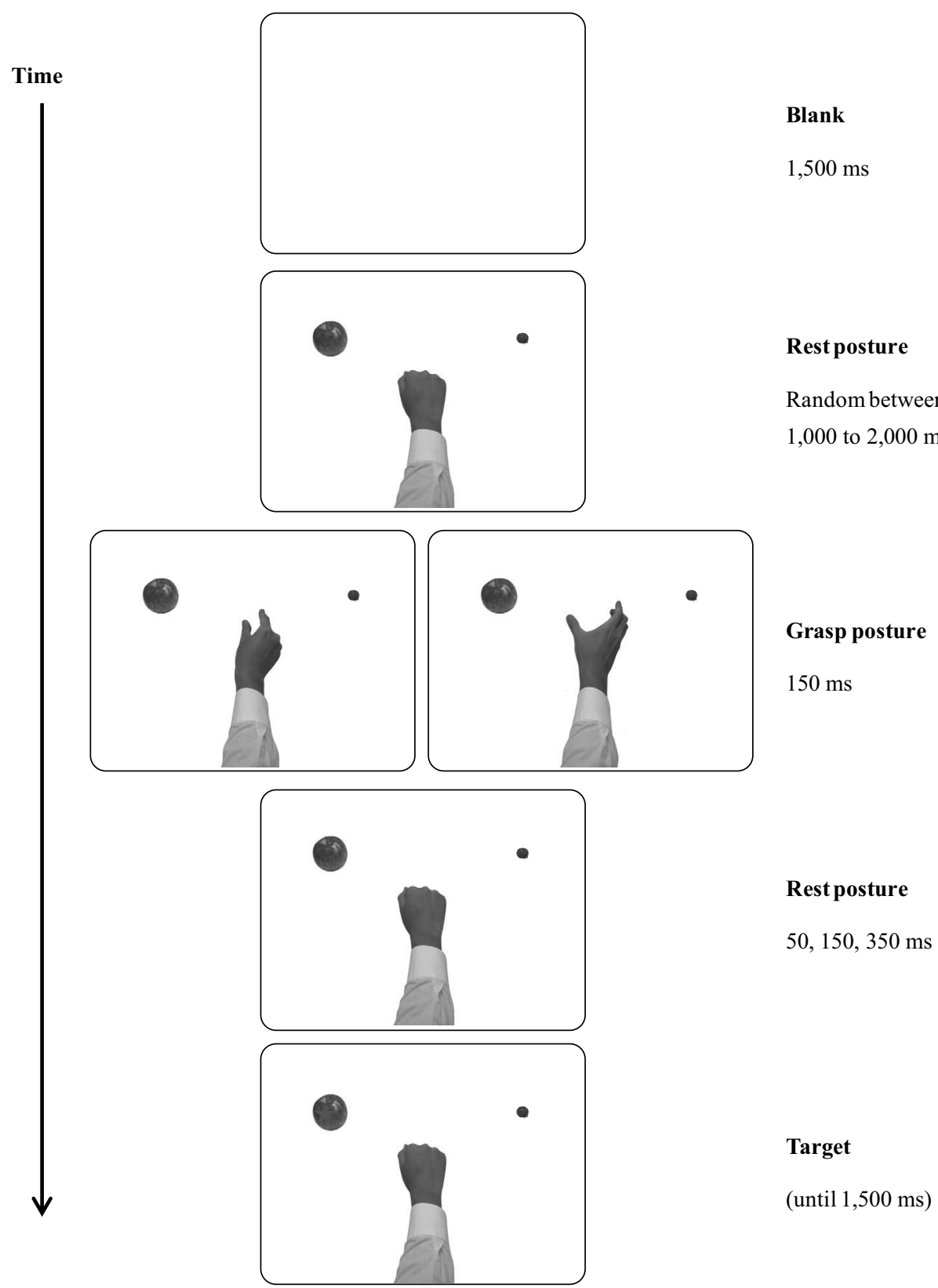

Figure 1. Sample trial sequence involving a simple reaction task. Depending on which panel in "Grasp posture" was presented, this sequence depicted an incongruent condition (left panel) or a congruent condition (right panel). The participants' task was to respond when the target stimulus (a red-colored star) was presented. 
一致条件では, SOA $200 \mathrm{~ms}$ と SOA $500 \mathrm{~ms}$ は SOA 300 $\mathrm{ms}$ よりもそれぞれ有意に反応時間が長かった（それ ぞれ $t(32)=4.80, p<.001, d=0.39 ; t(32)=2.37, p=$ $.02, d=0.23)^{1}$ 。本研究に重要な結果として, SOA 500 $\mathrm{ms}$ のときに一致性の単純主効果が有意となり, 一致 条件 $(M=298 \mathrm{~ms})$ の方が不一致条件 $(M=307 \mathrm{~ms})$ よりも反応時間が短かった $(F(1,32)=7.99, M S e=$ $\left.148.90, p=.01, \eta_{\mathrm{p}}^{2}=.20\right)$ 。SOA $200 \mathrm{~ms}$ と SOA $300 \mathrm{~ms}$ では一致性の単純主効果は有意ではなかった（それぞ れ $F(1,32)=1.70, M S e=85.46, p=.21, \eta_{\mathrm{p}}{ }^{2}=.05 ; F(1$, 32) $\left.=0.04, M S e=80.26, p=.84, \eta_{\mathrm{p}}^{2}=.001\right)$ 。

\section{考察}

本研究では, 把持行為を観察するときに起こる視覚 注意の調整が, 自己中心的視点から手を観察すること でもみられるのかどうかを検討した。その結果，把持 行為が提示されて $500 \mathrm{~ms}$ 経過した時点で, その行為 の意図に一致すると推測される対象物の上に提示され るターゲット刺激の検出時間が短くなることが示され た。この結果は, 自己中心的視点の刺激を用いても, 他者中心的視点の刺激による Fischer et al. (2008) の 研究と同様に把持手がかり効果がみられたことを示し ている。

視点の影響について, 本研究の結果は, 指差しとい う方向性を明示する刺激で，自己中心的視点の刺激と 他者中心的視点の刺激では同様の注意の調整効果があ るとする Belopolsky et al. (2008) の結果と一致する。 しかし, 本研究で用いた刺激は, 方向指示性のない把 持行為を示すものであった。実験では，把持行為の意 図に一致する対象物上にターゲット刺激が提示される 確率は $50 \%$ としており, 課題要求的にターゲットの 提示位置は予測できない。このような状況で注意の調 整効果がみられたという結果は, Fischer et al. (2008) や Lindemann et al.（2011） と同様, 実験参加者は把持 行為の刺激から何らかの推測をしていたことを示した といえる。このことに加え, これまでの研究では他者 が行為をしている様子を観察するような状況の刺激が 用いられていたが，本研究の結果は把持手がかり効果 が他者中心的視点の刺激に限って起こるものではない ことも示したといえる。

これらのことを踏まえると，把持手がかり効果には 把持行為の観察からその意図を推測することが特に重

1 把持手がかり効果について検討した先行研究 (Fischer et al., 2008; Lindemann et al., 2011; Tschentscher \& Fischer, 2008) におい ても SOAの主効果がみられ，特に短いSOA（遅延時間）におい て反応時間が長いことが示されている。これは課題特性による ものであると考えられるが, この結果を解釈することは本研究 の目的とは異なることに加え, 解釈を与えられるような条件設 定をしていないことから以降では取り上げない。
要であることを示しているとも考えられる。この推測 がどのようなメカニズムを反映しているかは本研究だ けでは結論づけられないが, 今回の結果は把持手がか り効果にミラーニューロンシステムが関わるとする Fischer et al. (2008) の考え方と一致するものといえる。 ただし，本研究の結果がミラーニューロンシステム による行為シミュレーションに基づくものであったと しても, 他者中心的視点の刺激でみられた効果と同一 のメカニズムで起こったかどうかは，本研究だけでは 明らかにできない点は留意しなければならない。

例えば，自己中心的視点の刺激において，他者中心 的視点の刺激と同様に視覚注意の調整効果がみられた 結果は, 自己中心的視点の刺激であっても, 参加者は それを他者の行為と認識したうえで，行為の意図を理 解しようとしていたという可能性を指摘できるかもし れない。本実験で使用した自己中心的視点の刺激は先 行研究に基づいて作成したものであり，自己の情報を 促進するものと考えられる。 Maeda, Kleiner-Fisman, \& Pascual-Leone (2002) は, 経頭蓋磁気刺激法 (transcranial magnetic stimulation）によって引き起こされた運動誘 発電位が，画面下から上に伸びた（natural hand orientation, つまり自己中心的視点の刺激のような） 手の写真を見ているときのほうが，画面上から下に伸 びた（unnatural hand orientation,つまり他者中心的視 点の刺激のような）手の写真を見ているときよりも大 きいことを示した。これは自己中心的視点の写真を見 ることで自己の運動に関連した神経活動が喚起される ことを示唆している。このことから, 本研究の刺激に

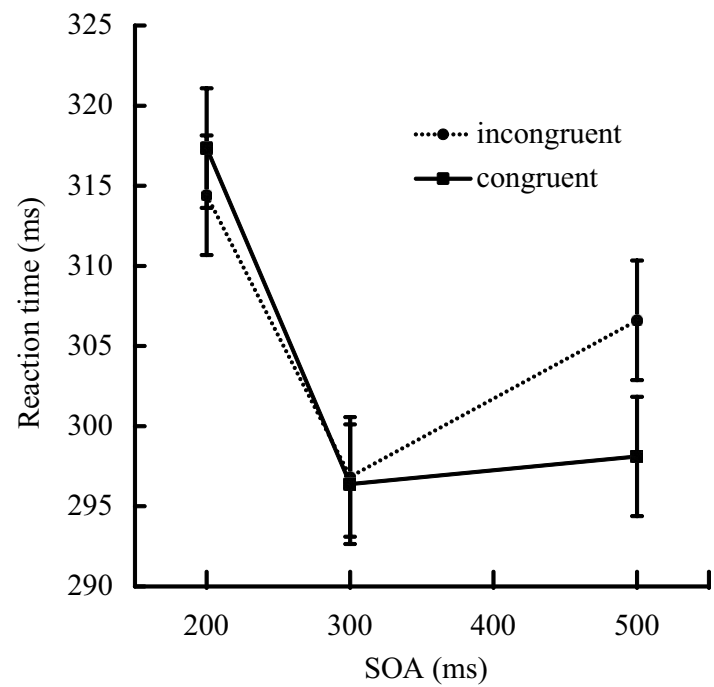

Figure 2. Mean reaction times in a simple reaction task as a function of target congruency and stimulus onset asynchrony (SOA).

Note. Error bars represent the $95 \%$ within-participant confidence interval (Loftus \& Masson, 1994). 
よっても自己に関連する情報の処理が起こるものと考 えられる。しかし, 実際に自己の行為として観察, 認 識していたかどうかは本研究の結果のみでは判断でき ない。把持手がかり効果にミラーニューロンシステム が関与しているのかをより明確するためにも, 本研究 で用いた自己中心的視点の刺激とともに他者中心的視 点の刺激を用い，その差異を直接的に比較する必要が あるといえよう。

本研究で示されたような把持手がかり効果は, 他者 中心的視点の刺激を用いたこれまでの研究では, 視線 注意の研究で説明されているような共同注意による処 理の促進的効果であると説明されている。しかし，把 持行為の観察は, 視線の観察とは異なる影響を与える ことも示唆されている。 Mazzarella, Hamilton, Trojano, Mastromauro, \& Conson（2012）は，他者の把持行為と 視線の観察が, 行為の目標となる対象物の位置を答え る際に自己と他者のどちらの視点から答えているのか を問う視点取得課題や対象物の検出課題に与える影響 について検討し, 把持行為の観察は他者中心的な視点 取得を促進させること, 視線の観察はその視線に一致 する方向に提示されるターゲット刺激の検出を促進さ せることを示した。Mazzarella et al.（2012）はこの結 果から, 把持行為と視線が社会的相互作用に扔いて異 なる認知メカニズムによって働いている可能性を指摘 している。マカクザルには視線運動の観察と制御に反 応するミラーニューロン様の神経細胞が存在すること が示唆されており (Shepherd, Klein, Deaner, \& Platt, 2009)，その知見を拡張すれば，視線観察による共同 注意もミラーニューロンシステムに基づく可能性も考 えられる。しかし，把持行為の観察による視覚注意の 調整は, これまでの研究で説明されるような共同注意 とは異なるメカニズムによって起こる可能性もあると 言える。このことから把持行為の観察による視覚注意 の調整が, 視線観察による視覚注意の調整とどのよう に異なるのかということについても検討する必要があ るだろう。

\section{引用文献}

Belopolsky, A. V., Olivers, C. N. L., \& Theeuwes, J. (2008). To point a finger: Attentional and motor consequences of observing pointing movements. Acta Psychologica, $128,56-62$.

Bruzzo, A., Borghi, A. M., \& Ghirlanda, S. (2008). Handobject interaction in perspective. Neuroscience Letters, 441, 61-65.

Downing, P. E., Dodds, M. C., \& Bray, D. (2004). Why does the gaze of others direct visual attention? Visual Cognition, 11, 71-79.

Fischer, M. H., Prinz, J., \& Lotz, K. (2008). Grasp cueing shows obligatory attention to action goals. Quarterly Journal of Experimental Psychology, 61, 860-868.

Fischer, M. H., \& Szymkowiak, A. (2004). Joint attention for pointing but not grasping postures. Cortex, 40, 168 -170 .

Frischen, A., Bayliss, A. P., \& Tipper, S. P. (2007). Gaze cueing of attention: Visual attention, social cognition, and individual differences. Psychological Bulletin, 133, 694-724.

Gallese, V., Fadiga, L., Fogassi, L., \& Rizzolatti, G. (1996). Action recognition in the premotor cortex. Brain, 119, 593-609.

Jansson, E., Wilson, A. D., Williams, J. H. G., \& MonWilliams, M. (2007). Methodological problems undermine tests of the ideo-motor conjecture. Experimental Brain Research, 182, 549-558.

Lindemann, O., Nuku, P., Rueschemeyer, S.-A., \& Bekkering, H. (2011). Grasping the other's attention: The role of animacy in action cueing of joint attention. Vision Research, 51, 940-944.

Loftus, G. R., \& Masson, M. E. J. (1994). Using confidence intervals in within-subject designs. Psychonomic Bulletin and Review, 1, 476-490.

Maeda, F., Kleiner-Fisman, G., \& Pascual-Leone, A. (2002). Motor facilitation while observing hand actions: Specificity of the effect and role of observer's orientation. Journal of Neurophysiology, 87, 1329-1335.

Mazzarella, E., Hamilton, A., Trojano, L., Mastromauro, B., \& Conson, M. (2012). Observation of another's action but not eye gaze triggers allocentric visual perspective. Quarterly Journal of Experimental Psychology, 65, 2447-2460.

Nuku, P., \& Bekkering, H. (2008). Joint attention: Inferring what others perceive (and don't perceive). Consciousness and Cognition, 17, 339-349.

Ristic, J., Friesen, C. K., \& Kingstone, A. (2002). Are eyes special? It depends on how you look at it. Psychonomic Bulletin and Review, 9, 507-513.

Rizzolatti, G., \& Craighero, L. (2004). The mirror-neuron system. Annual Review of Neuroscience, 27, 169-192.

Shepherd, S. V., Klein, J. T., Deaner, R. O., \& Platt, M. L. (2009). Mirroring of attention by neurons in macaque parietal cortex. Proceedings of the National Academy of Sciences of the United States of America, 106, 9489 $-9494$.

Tschentscher, N., \& Fischer, M. H. (2008). Grasp cueing and joint attention. Experimental Brain Research, 190, 493-498.

- 2013.11.8 受稿, 2014. 3.8 受理 